Research Article

\title{
Triband Operation Enhancement Based on Multimode Analytics of Modified Rhombic Ring Structure with Fractal Ring Parasitic
}

\author{
Chatree Mahatthanajatuphat (D), Thanakarn Suangun (iD, Norakamon Wongsin (D), \\ and Prayoot Akkaraekthalin $(i D)$
}

Department of Electrical and Computer Engineering, King Mongkut's University of Technology North Bangkok, Bangkok 10800, Thailand

Correspondence should be addressed to Prayoot Akkaraekthalin; prayoot.a@eng.kmutnb.ac.th

Received 19 April 2019; Revised 14 July 2019; Accepted 4 September 2019; Published 17 October 2019

Academic Editor: Symeon Nikolaou

Copyright (c) 2019 Chatree Mahatthanajatuphat et al. This is an open access article distributed under the Creative Commons Attribution License, which permits unrestricted use, distribution, and reproduction in any medium, provided the original work is properly cited.

\begin{abstract}
This paper presents a triband operation enhancement based on multimode analytics of a monopole antenna designed by combining a rhombic ring radiator with a strip on a top layer and a fractal ring resonator placed at the bottom layer. The proposed antenna can achieve triband operation to support the modern wireless communication systems. The antenna size is approximately $36 \times 52 \mathrm{~mm}^{2}$, which is quite compacted compared with the revised antenna. The simulation and measurement results are in good agreement. The antenna covers the operating bands at $22.22 \%, 9.8 \%$, and $31.27 \%$ at the resonant frequencies of $1.8 \mathrm{GHz}, 2.45 \mathrm{GHz}$, and $3.71 \mathrm{GHz}$, respectively, to support the application bands of LTE 1800, WLAN IEEE $802.11 \mathrm{~b} / \mathrm{g}$, WiMAX, and IMT Advanced Systems (5G). The average gain of the antenna is about $2 \mathrm{dBi}$. Also, the radiation patterns are omnidirectional for all operating frequencies.
\end{abstract}

\section{Introduction}

Rapid growth of wireless data communication is the main reason for consumer Internet access demand. Recently, most people do not have only one wireless mobile device accessing the Internet. To save costs and battery energy for the Internet connection, mobile hotspot [1] is a solution allowing many wireless devices to connect to it. Since multiple frequency operation is the main function of the mobile hotspot, a multiband antenna as an important part of a front-end mobile hotspot should be desirable.

The literature review shows that multiband antennas can be categorized into two types: wideband antennas with notch frequency [2-7] and multiband antennas with multiple resonators [8-14]. In [2], the wideband antenna with notch frequency composed of a swallowtail patch, trapezoid ground, and three split ring resonators was proposed. The triple band notch was generated by the three split ring resonators placed on the radiation patch. Also, a capacitance compensation was added at the backside of the patch to improve impedance bandwidth. In [3], a dual-band antenna has been created using a novel planar printed dipole. The antenna consists of a bow-tie patch and a semicircular loop operating as electric and magnetic dipoles, respectively. A pair of capacitive-loaded loop slots was etched on the bowtie patch to introduce a notched band performing the dualband operation. A wideband antenna with multiple notches was proposed in [4]. The antenna was designed as a circular patch that works like a radiator and the systematic defection slots in coplanar ground obtaining multiple notch frequencies. Also, a wideband antenna with a notch using a quarter wavelength strip has been proposed in [5]. The antenna radiator was etched by a milling machine to create the strip acting as a nonradiating load at the suppression frequency, resulting in a notched frequency occurrence. In [6], a wideband slot antenna with dual notched frequency has been proposed. It consists of two pairs of narrow slits in the ground plane for the dual-band frequency rejection. A 
wideband antenna based on a rectangular stepped slot has been proposed in [7]. Two C-shaped resonators were placed adjacent to the transmission line to produce a notch frequency. The disadvantage of the antennas in [2-7] is that the operating frequency bands could not be independently controlled and the antenna radiation patterns were unusual due to the higher-order radiating modes of the antenna.

Then, a multiband monopole antenna with two inverted L slots has been proposed to achieve triple operating frequency bands in [8]. The antenna was fed by a coplanar waveguide $(\mathrm{CPW})$. The substrate rectangles were cut off at two corners to improve impedance bandwidth and matching. However, it did not cover the global frequency band of WiMAX applications. Also, a novel multiband antenna using a Kapton polyimide flexible substrate fed by a CPW has been proposed in [9]. The antenna includes multitriangular radiators and a circular-shaped ground plane, resulting in the multiple resonance frequencies depending on each radiator's triangular height. The disadvantage of this antenna is the difficulty to obtain a highquality antenna because the conductor created by inkjetprinting is of anisotropic material. In [10], a penta-band slot dipole antenna has been proposed. The antenna is created by etching the comb-like slots on metal sheets. Each slot can independently control a resonant frequency of the antenna; however, the antenna has a large dimension. Also, a bow-tie monopole antenna was proposed in [11]. The antenna is constructed by etching slots of different lengths in a bow-tie to achieve the multiband operation. In [12], a dual-band monopole antenna has been proposed. The dual-band operation is generated by a monopole radiator and embedded slots with rectangular patches. In $[11,12]$, the resonant frequencies could be independently controlled, but the antenna dimensions are still large. Likewise, a multiband antenna with an L-shaped parasitic strip has been proposed in [13]. The antenna comprises of a planar inverted L-shaped radiator and an L-shaped parasitic strip. The first and third resonant frequencies were generated by the radiator as the placing of the parasitic strip on the radiator's back creates the second resonant frequency and improves the impedance bandwidth of the antenna. However, the radiation patterns of the antenna are distorted due to the asymmetrical structure of the antenna. In [14], a monopole antenna has been modified to a fork-shaped structure producing dualfrequency bands. By adding an L-shaped parasitic strip on the opposite substrate layer, the antenna achieves triple frequency bands and improved impedance matching. However, antenna production is very complicated because it has more than one parasitic strip on the bottom layer of the antenna. It can be concluded that the multiband antennas with multiple resonators in [8-14] can independently control the resonant frequencies which is usually caused by the patterns radiated by the fundamental mode of the antenna.

In this paper, a rhombic ring monopole antenna with strip and a ring resonator in [15] is modified and presented to generate the operating frequency bands of LTE 1800 (Long Term Evolution) $1710-1880 \mathrm{MHz}$, WLAN IEEE802.11b/g (Wireless Local Area Network) 2400-2484 MHz, WiMAX
(Worldwide Interoperability for Microwave Access) 3.3$3.8 \mathrm{GHz}$, and IMT Advanced Systems (5G) 3.3-4.2 GHz. Especially, the ring resonator is modified by applying the Koch fractal model, resulting in the physical length reduction as reviewed in [16-19]. Fractal geometry has been proven to be useful to design an antenna such as multiband and achieve miniaturization. Also, the presented antenna will be developed and enhanced with triband operations based on the multimode analytics in a limited dimension supporting the required operating frequency bands. The parameter values of the presented antenna were determined and optimized by using the CST software. The function of a prototype of the presented antenna has been confirmed by measurement. The organization of this paper is the following. In Section 2, the design of the presented antenna is given and described in detail. The function of the antenna is verified by multimode and surface current distribution analysis. Simulation and experiment results of the antenna will be analyzed in Section 3. Finally, the conclusions of the presented antenna are discussed in Section 4.

\section{Antenna Design}

Figure 1(a) shows the configuration of the antenna presented in this paper. It is designed on an FR-4 substrate with a relative permittivity $\left(\varepsilon_{\mathrm{r}}\right)$ of 4.2 , thickness $(h)$ of $1.6 \mathrm{~mm}$, and loss tangent $(\tan \delta)$ of 0.019 . The proposed antenna composes of a rhombic ring radiator, a strip, and a fractal ring resonator. Typically, the rhombic ring radiator on the top layer is created to support the $1.8 \mathrm{GHz}$ frequency band. To radiate the electromagnetic wave at the frequency band of $3.5 \mathrm{GHz}$, the rhombic ring radiator is modified by adding a strip monopole antenna inside the radiator. Moreover, a fractal ring resonator, which is created by generating the first iteration of the Koch fractal model [20], Figure 1(b), on all sides of a rectangular ring resonator, is placed near the position of the strip on the bottom layer for resonating the frequency at $2.45 \mathrm{GHz}$ and improving the impedance bandwidth at $3.5 \mathrm{GHz}$. As shown in Figure $1(\mathrm{a})$, the proposed antenna is fed by the $50 \Omega$ microstrip line $\left(W_{\mathrm{t}}=3 \mathrm{~mm}\right)$ with SMA connector. The optimal parameter values for designing the proposed antenna are summarized in Table 1.

2.1. Mode Analysis. Typically, a rhombic ring monopole antenna can be created simply as shown in Figure 2(a). The length of the monopole antenna is designed on the fundamental resonant frequency at $1.8 \mathrm{GHz}$, which can be estimated with a quarter effective wavelengths by

$$
f_{1.8 \mathrm{GHz}}=\frac{3 \times 10^{8}}{4 \sqrt{0.35\left(\varepsilon_{\mathrm{r}}+1\right)} \cdot\left(\sqrt{2} \cdot L_{\mathrm{r}}\right)},
$$

where $L_{\mathrm{r}}$ is the length of each side of the rhombic ring. As the antenna is excited by the $50 \Omega$ microstrip line, it generates dual modes and dual-frequency resonances as illustrated by the reflection coefficients in Figure 2(b). The results show the resonant frequencies at $1.88 \mathrm{GHz}$ and $4.4 \mathrm{GHz}$, which are the first and third resonant modes of the rhombic ring, respectively. Figures 2(c) and 2(d) depict the surface current 


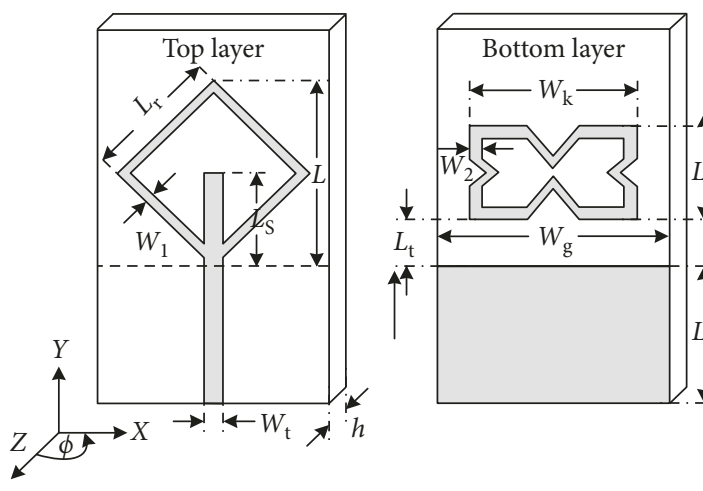

(a)

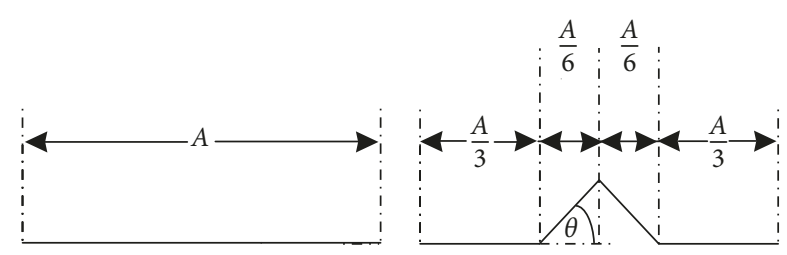

(b)

Figure 1: (a) The configuration of the proposed antenna and (b) the initial generator model of the Koch fractal.

TABLE 1: The presented antenna parameters.

\begin{tabular}{lc}
\hline Parameter & Value \\
\hline$\theta$ & $51.03^{\circ}$ \\
$L_{\mathrm{g}}$ & $22 \mathrm{~mm}$ \\
$L_{\mathrm{k}}$ & $15 \mathrm{~mm}$ \\
$L_{\mathrm{r}}$ & $21.21 \mathrm{~mm}$ \\
$L_{\mathrm{s}}$ & $15 \mathrm{~mm}$ \\
$L_{\mathrm{t}}$ & $7.5 \mathrm{~mm}$ \\
$h$ & $1.6 \mathrm{~mm}$ \\
$W_{1}$ & $2 \mathrm{~mm}$ \\
$W_{2}$ & $2 \mathrm{~mm}$ \\
$W_{\mathrm{g}}$ & $36 \mathrm{~mm}$ \\
$W_{\mathrm{k}}$ & $26 \mathrm{~mm}$ \\
$W_{\mathrm{t}}$ & $3 \mathrm{~mm}$ \\
\hline
\end{tabular}

distributions on the rhombic ring at the resonant frequencies of $1.88 \mathrm{GHz}$ and $4.4 \mathrm{GHz}$. As the surface current distributions flow along the rhombic ring, it has been seen that one null node exists at $1.88 \mathrm{GHz}$ and three null nodes occurred at $4.4 \mathrm{GHz}$, resulting in the rhombic ring resonating at the first and third modes, respectively. Also, the rhombic ring operates at the odd mode being the radiating mode, while the even mode of the rhombic ring is the nonradiating mode. Since the frequency band of $4.4 \mathrm{GHz}$ cannot cover the application requirement of IMT Advanced Systems (5G) 3.3-4.2 GHz, the antenna was redesigned by adding a strip inside the rhombic ring to resonate at $3.5 \mathrm{GHz}$ to cover the application requirements.

Before adding the strip inside the rhombic ring, the mechanism of the strip must be verified by mode analysis. As shown in Figure 3(a), a strip monopole antenna with a quarter effective wavelength resonating at the frequency of $3.5 \mathrm{GHz}$ can be calculated by

$$
f_{3.5 \mathrm{GHz}}=\frac{3 \times 10^{8}}{4 \sqrt{0.35\left(\varepsilon_{\mathrm{r}}+1\right)} \cdot\left(L_{\mathrm{S}}\right)},
$$

where $L_{\mathrm{s}}$ is the length of strip line. As the antenna was excited, the antenna resonated at $3.8 \mathrm{GHz}$ as depicted by the reflection coefficient in Figure 3(b). The current distribution at $3.8 \mathrm{GHz}$ is shown in Figure 3(c). It was found that no null node exists on the antenna. Thus, the radiating mode of the strip is the first mode or odd mode at $3.8 \mathrm{GHz}$ while the even mode is the nonradiating mode.

When the strip added within the rhombic ring is excited by the feed line as shown in Figure 4(a), resonances occur at $1.8 \mathrm{GHz}$ and $3.9 \mathrm{GHz}$. Especially, the resonant frequency of $1.8 \mathrm{GHz}$ is generated by the first resonant mode of the rhombic ring while the resonant frequency $3.9 \mathrm{GHz}$ is created by combining the third resonant mode of the rhombic ring and the first resonant mode of the strip, resulting from the coupling effect between the rhombic ring and the strip. Also, the rhombic ring monopole with strip can cover the operating frequency bands of the LTE 1800, WiMAX, and IMT Advanced Systems (5G). To improve the frequency band of the rhombic ring monopole antenna with strip and add support of WLAN, a resonator operating at $2.45 \mathrm{GHz}$ should be added on the backside of the antenna. The length of a fractal ring resonator operating at $2.45 \mathrm{GHz}$ can be approximated by

$$
f_{2.45 \mathrm{GHz}}=\frac{3 \times 10^{8}}{\sqrt{0.35\left(\varepsilon_{\mathrm{r}}+1\right)} \cdot\left[2 / 3 \cdot\left(W_{\mathrm{k}}+L_{\mathrm{k}}\right) \cdot(2+\sec \theta)\right]},
$$

where $W_{\mathrm{k}}$ and $L_{\mathrm{k}}$ are the lengths of the fractal ring resonator. The mechanism of a fractal ring resonator has been investigated in Figure 5. When the configuration of the fractal ring resonator is excited independently as shown in Figure 5(a), it generates the first resonant frequency of $3 \mathrm{GHz}$ as depicted in Figure 5(b). Current distribution along the resonator at $3 \mathrm{GHz}$ is shown in Figure 5(c) reveals that there are two null nodes in it, resulting in the resonator radiating in the second mode or even mode. Accordingly, the electrical length of the antenna is about $\lambda_{\mathrm{g}}$. As shown in Figure 6, the antenna resonates at $1.8 \mathrm{GHz}, 2.45 \mathrm{GHz}$, $3.24 \mathrm{GHz}$, and $4.04 \mathrm{GHz}$ supporting the frequency bands of 1.65-1.96 GHz, $2.36-2.56 \mathrm{GHz}$, and $3.1-4.2 \mathrm{GHz}$, respectively, at $\left|S_{11}\right|$ level $<-10 \mathrm{~dB}$. Particularly, the resonant of $3.24 \mathrm{GHz}$ and $4.04 \mathrm{GHz}$ occurred by splitting off between the first and third modes of the strip and the rhombic ring radiator at the previous resonant frequency of $3.9 \mathrm{GHz}$, respectively, due to the coupling effect between the fractal ring resonator and the rhombic ring with the strip. 


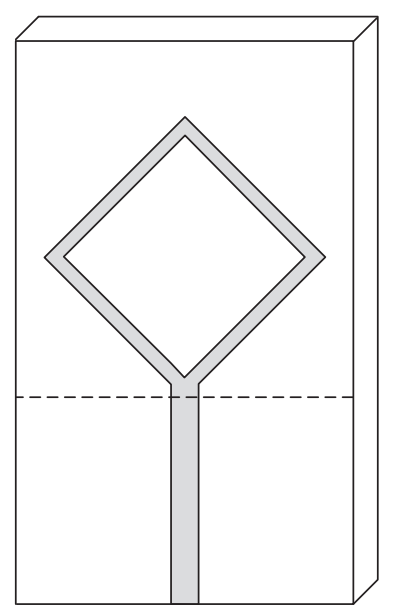

(a)

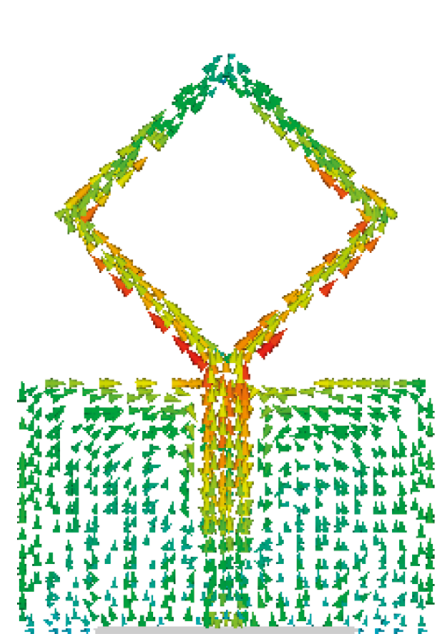

(c)

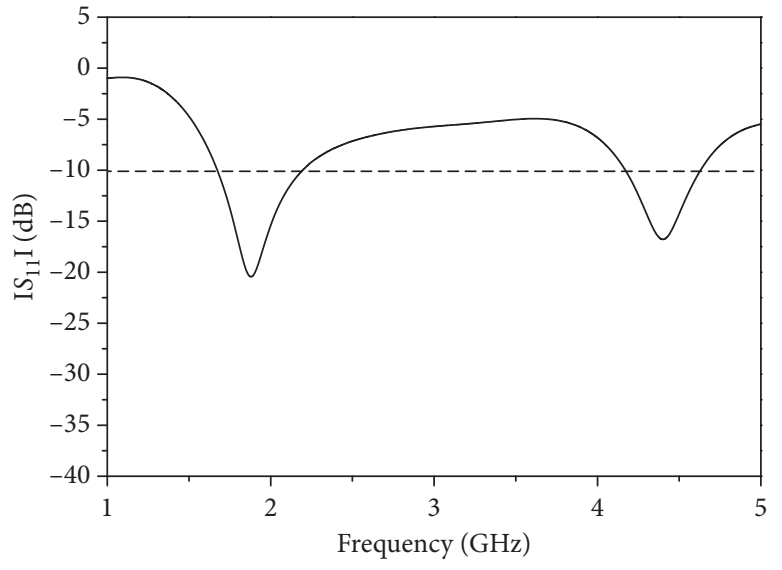

(b)

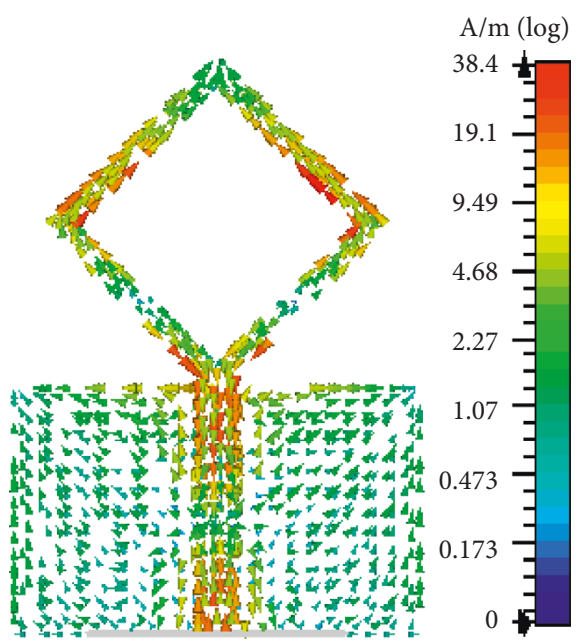

(d)

FIgUre 2: Mode analysis of the rhombic ring. (a) Configuration of the rhombic ring. (b) Reflection coefficients. (c) Current distribution at $1.88 \mathrm{GHz}$. (d) Current distribution at $4.04 \mathrm{GHz}$.

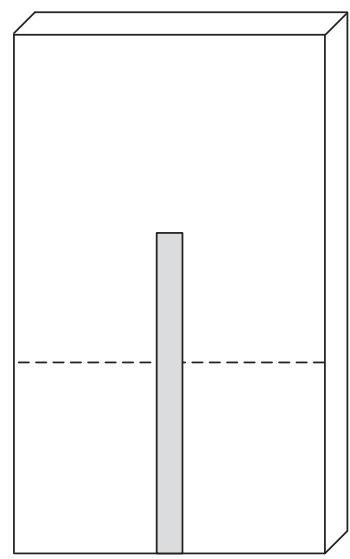

(a)

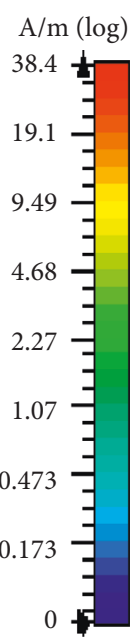

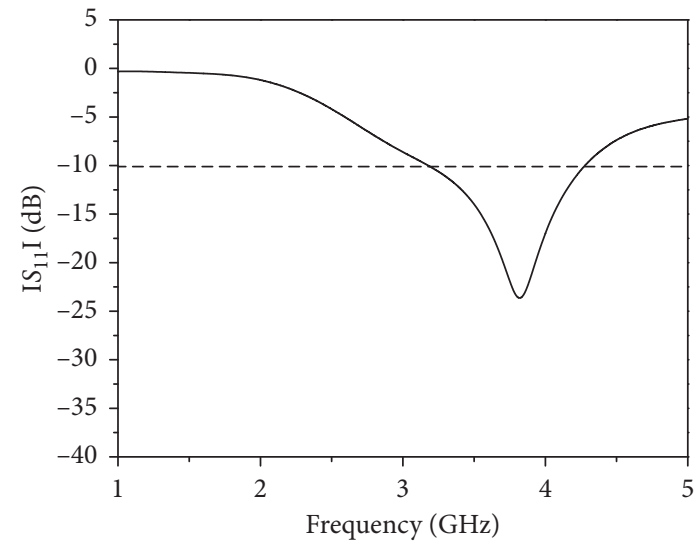

(b)

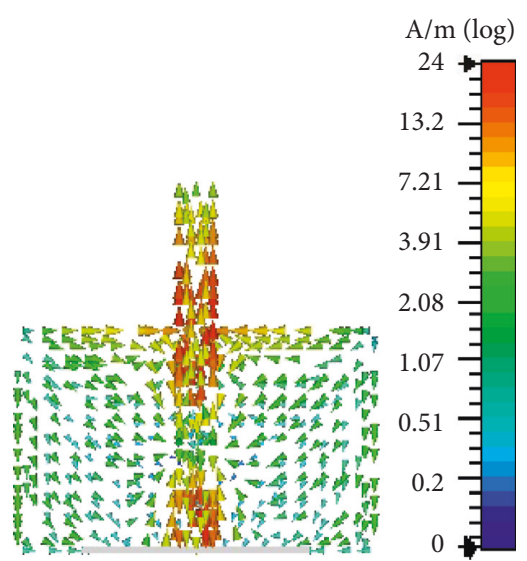

(c)

FIgure 3: Mode analysis on the strip. (a) Configuration of the strip. (b) Reflection coefficients. (c) Current distribution at 3.8 GHz.

To study the effect of the geometric parameters of the proposed antenna, the parameters of $L_{\mathrm{r}}, W_{\mathrm{k}}$, and $L_{\mathrm{s}}$ are investigated further. The effect of a varying parameter $L_{\mathrm{r}}$ on the reflection coefficient of the antenna is shown in Figure 7(a). It can be noticed that the resonant frequencies of $1.8 \mathrm{GHz}$ and $4.04 \mathrm{GHz}$ shift to a lower frequency as the $L_{\mathrm{r}}$ 


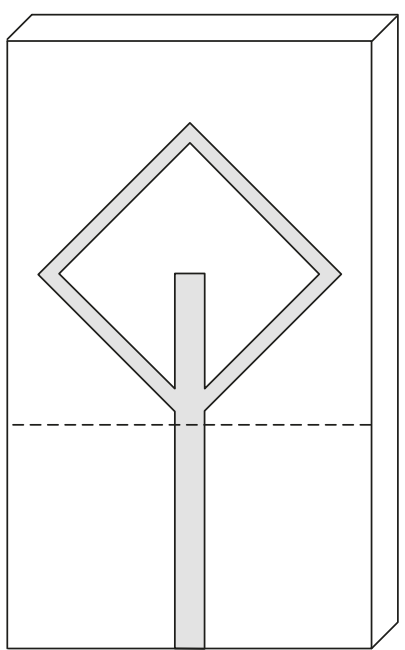

(a)

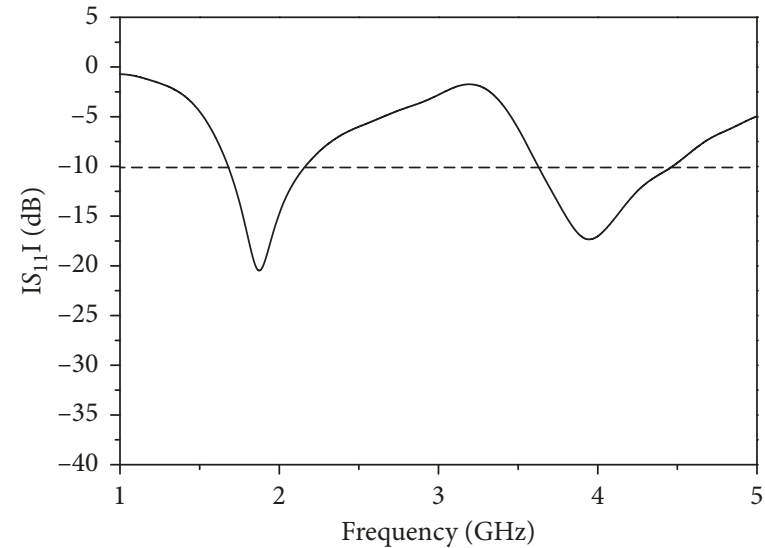

(b)

Figure 4: (a) Configuration of the rhombic ring with strip and (b) reflection coefficients.

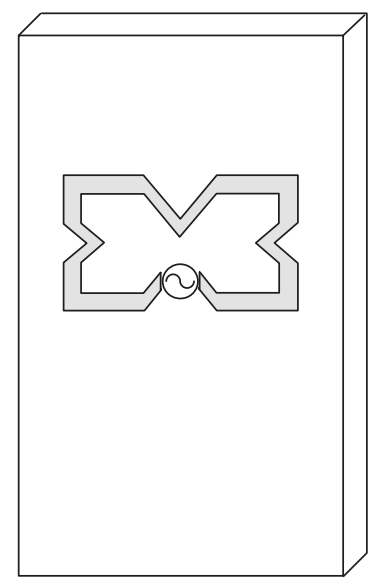

(a)

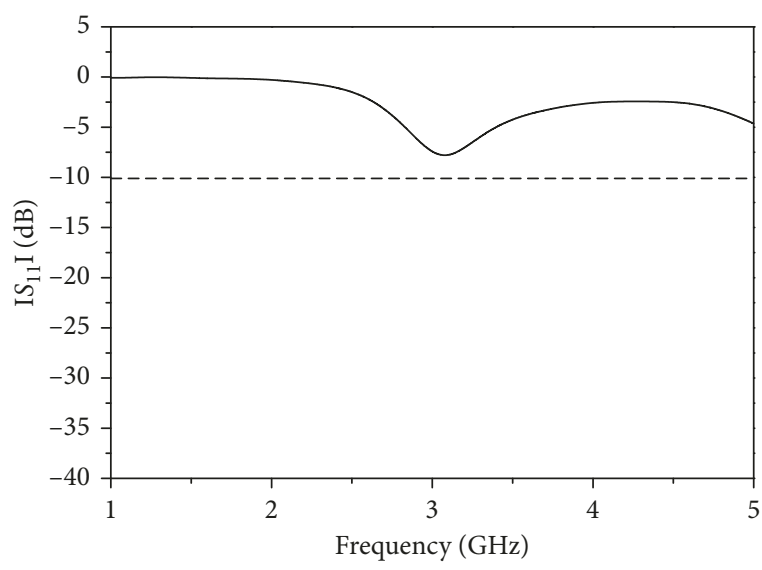

(b)

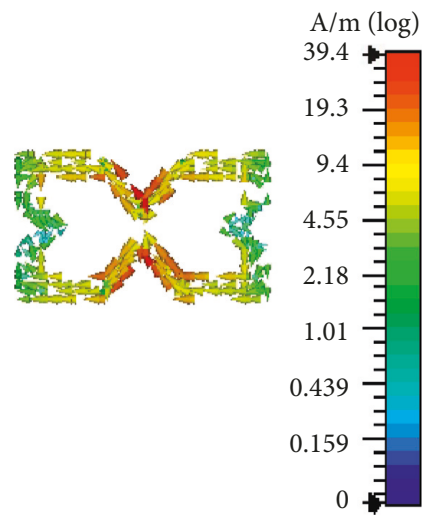

(c)

Figure 5: Mode analysis of the Koch fractal ring resonator. (a) Configuration of the Koch fractal ring resonator. (b) Reflection coefficients. (c) Current distribution at $3 \mathrm{GHz}$.

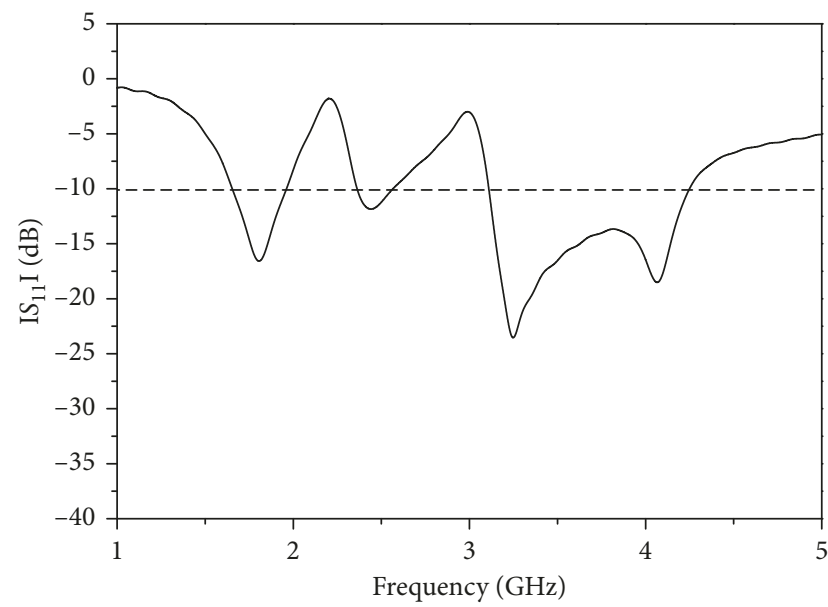

Figure 6: The reflection coefficient of the rhombic ring with strip and Koch fractal ring resonator. parameters increase, which is caused by the extended electrical length of the rhombic ring monopole antenna according to the first and third radiating modes of the rhombic ring antenna. Nevertheless, the impedance matching of the antenna is degenerated at $3.24 \mathrm{GHz}$ due to the coupling effect between the rhombic ring and the strip line.

The frequency responses of the antenna with an increasing parameter $W_{\mathrm{k}}$ are depicted in Figure $7(\mathrm{~b})$. It has been seen that the frequency of $2.45 \mathrm{GHz}$ shifts to a lower frequency due to the expanded electrical length of the fractal ring resonator, while the impedance bandwidth and matching at the third frequency band is changed because the extending length of the resonator disturbs the coupling effect between the rhombic ring and strip. As shown in Figure 7(c), when varying the parameter $L_{\mathrm{s}}$, the resonant frequency of $3.24 \mathrm{GHz}$ is shifted to a lower frequency resulting from the increase of the electrical length of the strip. However, the 


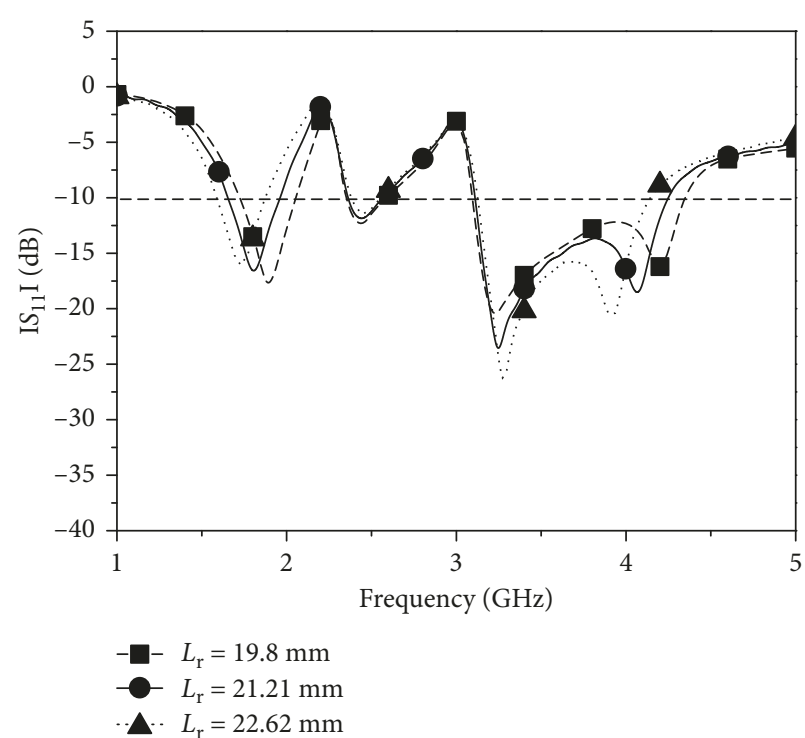

(a)

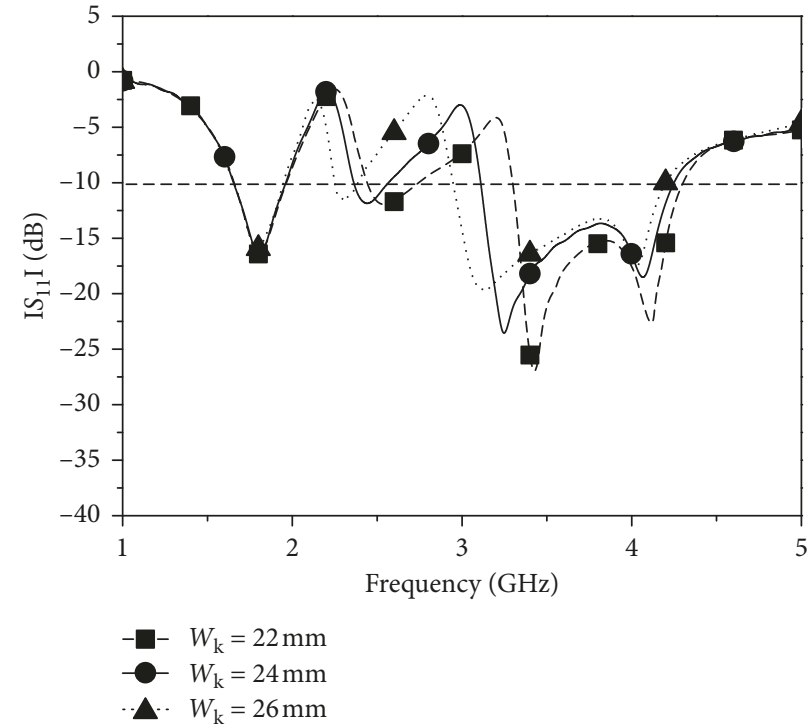

(b)

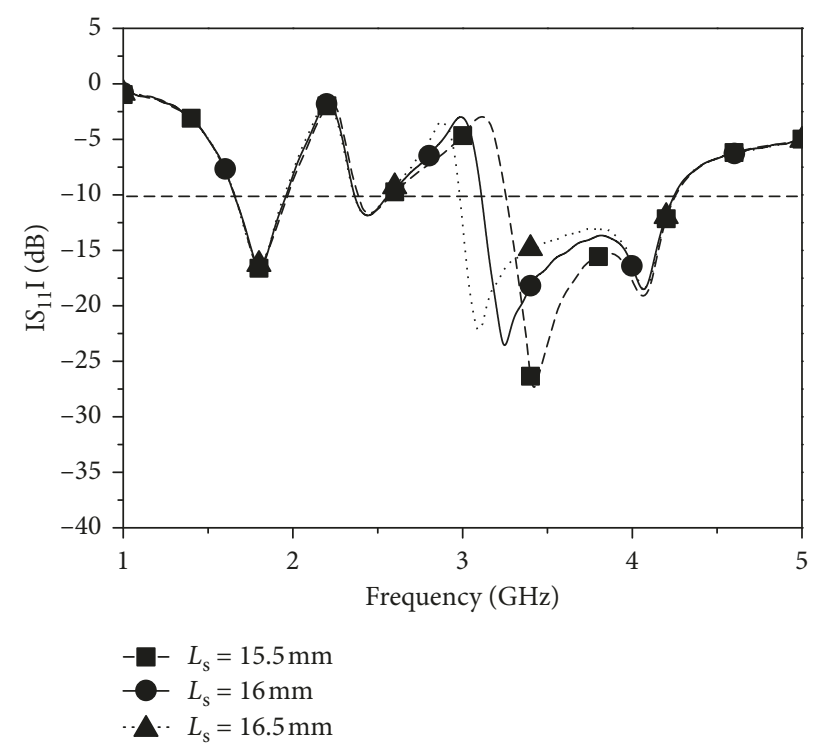

(c)

FIGURE 7: Simulated reflection coefficients with varying the parameters of (a) $L_{\mathrm{r}}$, (b) $W_{\mathrm{k}}$, and (c) $L_{\mathrm{s}}$.

parameters of $L_{\mathrm{r}}, W_{\mathrm{k}}$, and $L_{\mathrm{s}}$ can be optimized by the simulation software for improving the impedance bandwidth and matching of the presented antenna. Then, the surface current distributions of the optimized antenna will be shown and discussed in detail further on.

2.2. Surface Current Distribution. To investigate the mechanism of the proposed antenna, the surface current distributions on the rhombic ring radiator, strip, and the fractal ring resonator are discussed. As mentioned in the previous subsection, the proposed antenna can achieve multiple resonant frequencies of $1.8 \mathrm{GHz}, 2.45 \mathrm{GHz}, 3.24$, and $4.04 \mathrm{GHz}$. Therefore, various surface current distributions based on the resonant frequencies of reflection coefficients on the antenna are carried out by the simulation software. Figure 8(a) shows the surface current distribution on the proposed antenna at $1.8 \mathrm{GHz}$. Since the height of the rhombic ring radiator is approximately at quarter effective wavelength $\left(0.28 \lambda_{\mathrm{g}}\right)$, the major current distribution occurs on the edge of the rhombic ring radiator. It has been indicated that the current flows up to the highest position of the rhombic ring radiator and has a null node on it. Meanwhile, the current distributions on the strip and the fractal ring resonator are minor. Then, it can be neglect because the first radiating mode of the strip is not at the frequency of $1.8 \mathrm{GHz}$ and also the fractal ring resonator cannot radiate the electromagnetic wave in the first mode. Consequently, the rhombic ring radiator can radiate the wave at $1.8 \mathrm{GHz}$ independently and does not disturb the 

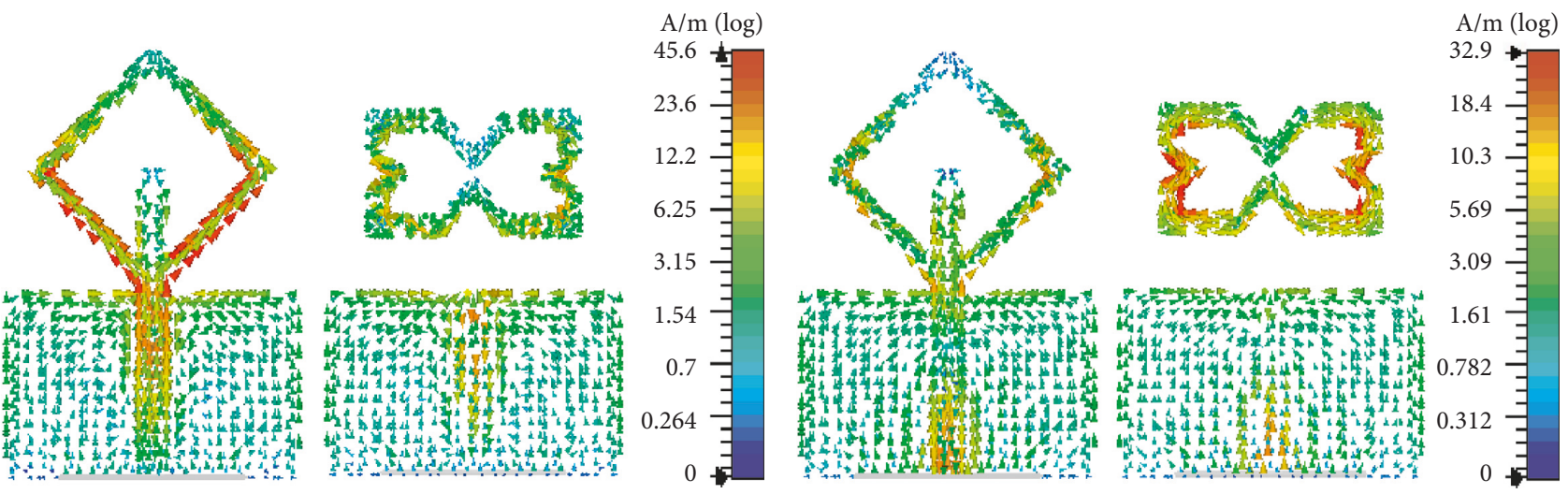

(a)

(b)
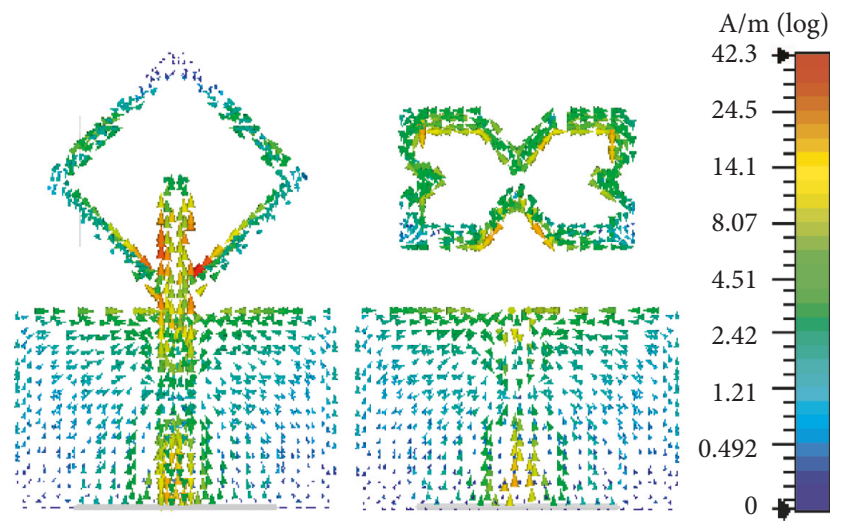

(c)
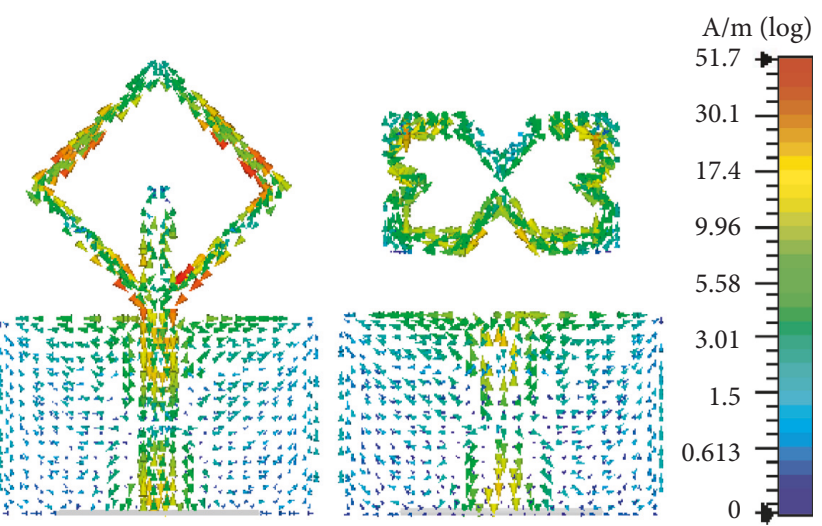

(d)

FIGURE 8: Surface current distribution on the top and bottom layer of the presented antenna at the operating frequencies of (a) $1.8 \mathrm{GHz}$, (b) $2.45 \mathrm{GHz}$, (c) $3.24 \mathrm{GHz}$, and (d) $4.04 \mathrm{GHz}$.

nonradiating mode of the strip and the fractal ring resonator.

At the frequency of $2.45 \mathrm{GHz}$, the surface current distribution is studied as shown in Figure 8(b). It has been shown that major current distributions exist on the strip and the fractal ring resonator, while the current distribution on the rhombic ring radiator is neglectable. As a result, it has been seen that the rhombic ring radiator cannot propagate the electromagnetic wave due to the radiator working in a state of nonradiating mode at this frequency. Although the major current passes along on the strip, it cannot propagate the wave because the first radiating mode of the strip is not at this frequency. Therefore, the strip acts as feed line coupling the electromagnetic field to the fractal ring resonator. Then, the fractal ring resonator is excited by the feed strip and mainly propagates the electromagnetic wave in a state of radiating mode at $2.45 \mathrm{GHz}$. Also, the resonator has two null nodes due to its resonance at the second mode and the electrical wavelength on the fractal ring resonator is about $1.15 \lambda_{\mathrm{g}}$ according to the major current distribution on it.

The current distribution at $3.24 \mathrm{GHz}$ is depicted in Figure $8(\mathrm{c})$. The result reveals a minor current flow through the rhombic ring radiator and the fractal ring resonator while the major current exists on the strip. As a result, the rhombic ring and fractal ring resonator behave as a load to improve impedance matching and bandwidth when in a state of nonradiating mode at $3.24 \mathrm{GHz}$. Conversely, the strip operates at the radiating mode at $3.24 \mathrm{GHz}$ and there is no null node on the strip. As a result, the strip operates in the first mode. Moreover, the electrical wavelength on the strip is approximately $0.25 \lambda_{\mathrm{g}}$ corresponding to the major current distribution on it.

As illustrated in Figure 8(d), at $4.04 \mathrm{GHz}$, it can be found that the major current distribution appears on the rhombic ring radiator with three null nodes and minor current distributions exist on the strip and the fractal ring resonator. The rhombic ring operating in the third radiating mode is the main radiator to propagate the electromagnetic wave at $4.04 \mathrm{GHz}$. Hence, the strip and the fractal resonator performing in the state of nonradiating mode cannot propagate the wave.

As verified by the surface current distribution analysis on the proposed antenna, it can be concluded that the antenna supports multiple resonant frequencies with the multimode. At the first resonant frequency, the rhombic ring radiator operates in the odd radiating mode (the first mode). Also, the fractal ring resonator radiates in the even radiating mode (the second mode) at the second resonant frequency. The third resonant frequency is created next by the first mode of the strip. Finally, the fourth resonant frequency is generated 


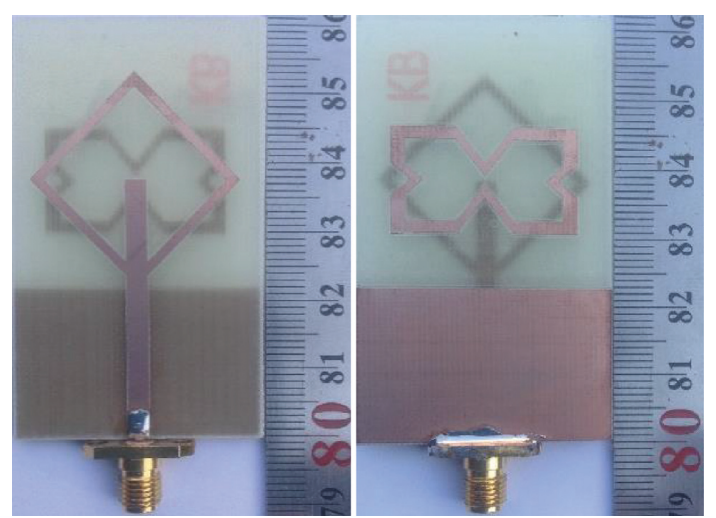

FIGURE 9: A prototype of the presented antenna.

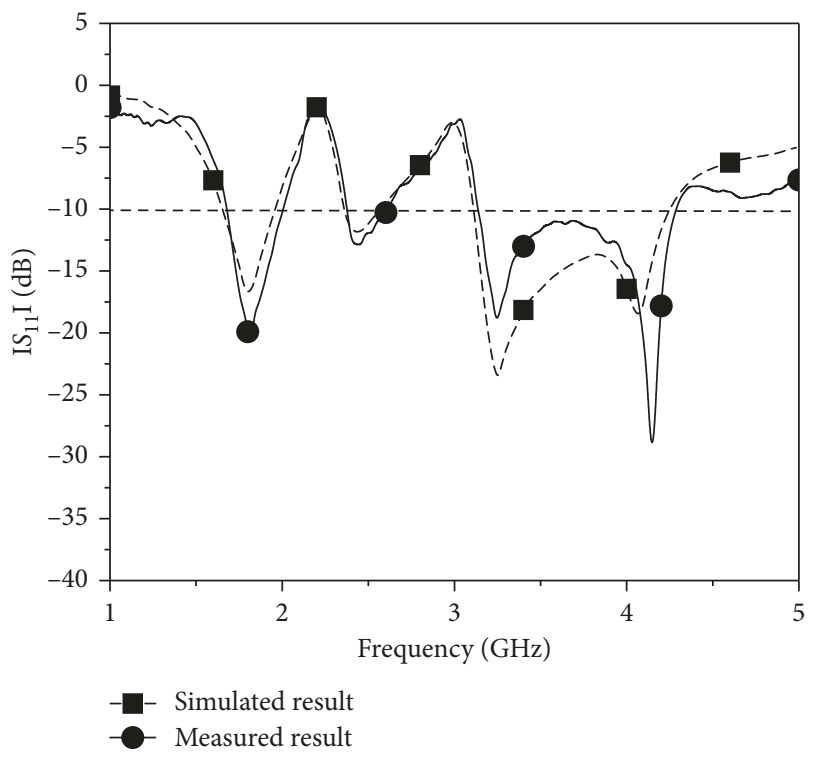

FIGURE 10: Simulated and measured $\left|S_{11}\right|$ of the presented antenna.

by the third mode of the rhombic ring radiator, which is the odd radiating mode.

\section{Simulation and Experiment}

The proposed antenna is then fabricated by mechanical etching and is shown in Figure 9. The optimal parameters are shown in Table 1. In the experiment, the antenna reflection coefficients were measured by the Rohde \& Schwarz ZVB20 VNA. The results shown in Figures 6 and 10 indicate that the operating frequency bands and impedance matching are depended on the electromagnetic coupling effect between the rhombic ring with strip and the Koch fractal ring resonator. Also, the simulated and measured results of antenna agree well. However, the simulated and measured results are slightly different in the third operating frequency band due to a faulty placement of the rhombic ring radiator on the top layer and the Koch fractal ring resonator on the bottom layer of the antenna.

The simulated and measured gains are illustrated in Figure 11. In the first operating frequency band, the average measured gain is approximately $2 \mathrm{dBi}$ and about $2.5 \mathrm{dBi}$ in the

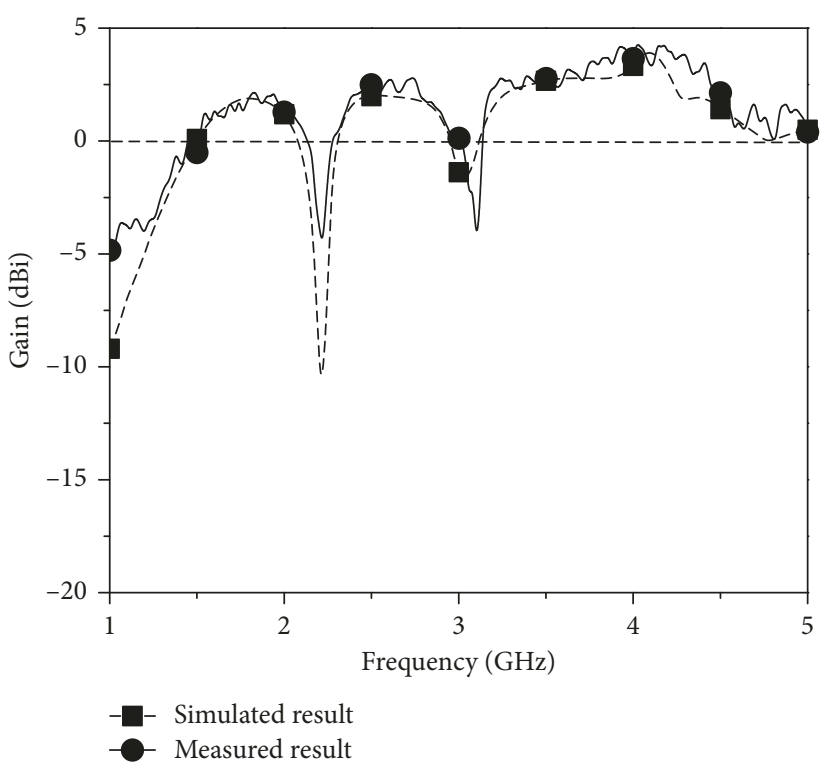

FIgURE 11: Simulated and measured gains at $\phi=0$ degrees in the $X$ $Z$ plane of the presented antenna.

second and third operating frequency band. While the maximum gain of $4.35 \mathrm{dBi}$ is approached at the higher frequency band of $4 \mathrm{GHz}$, it has been found that the maximum gain is produced by combining the electromagnetic fields between the third mode of the rhombic ring radiator and the first mode of the strip. A good agreement of antenna gain is achieved between the simulated and measured results.

The antenna patterns were measured in an anechoic chamber. Figures 12(a) and 12(b) show the simulated and measured radiation patterns in the $X-Z$ plane and $Y-Z$ plane at the operating frequencies of $1.8 \mathrm{GHz}, 2.45 \mathrm{GHz}, 3.24 \mathrm{GHz}$, and $4.04 \mathrm{GHz}$, respectively. The radiation patterns of the proposed antenna are omnidirectional at all operating frequencies as illustrated in Figure 12. It can be noticed that the magnitudes of cross-polarization in $X-Z$ and $Y-Z$ planes are below $-18 \mathrm{~dB}$. Also, the peak gains of the antenna are exhibited at 0 and 180 degrees at the frequencies of $1.8 \mathrm{GHz}$, $2.45 \mathrm{GHz}$, and $3.24 \mathrm{GHz}$. However, at $4.04 \mathrm{GHz}$, the peak gains of the antenna exist at 15 and 165 degrees due to the antenna operating at the third radiating mode.

\section{Conclusions}

A triple-band enhancement based on multimode analytics with strip and Koch fractal ring resonator has been proposed and compared with other antennas as shown in Table 2. The impedance bandwidth and dimension can be improved by the electromagnetic coupling effect among the rhombic ring radiator with strip and the Koch fractal ring resonator to cover the three operation frequency bands for applications in LTE 1800 (Long Term Evolution) 1.71-1.88 GHz, WLAN IEEE $802.11 \mathrm{~b} / \mathrm{g}$ (Wireless Local Area Network) 2.4$2.484 \mathrm{GHz}$, WiMAX (Worldwide Interoperability for Microwave Access) 3.3-3.8 GHz, and IMT Advanced Systems $(5 \mathrm{G}) 3.4-4.2 \mathrm{GHz}$. The investigation revealed that the first band is produced by the first mode of the rhombic ring 

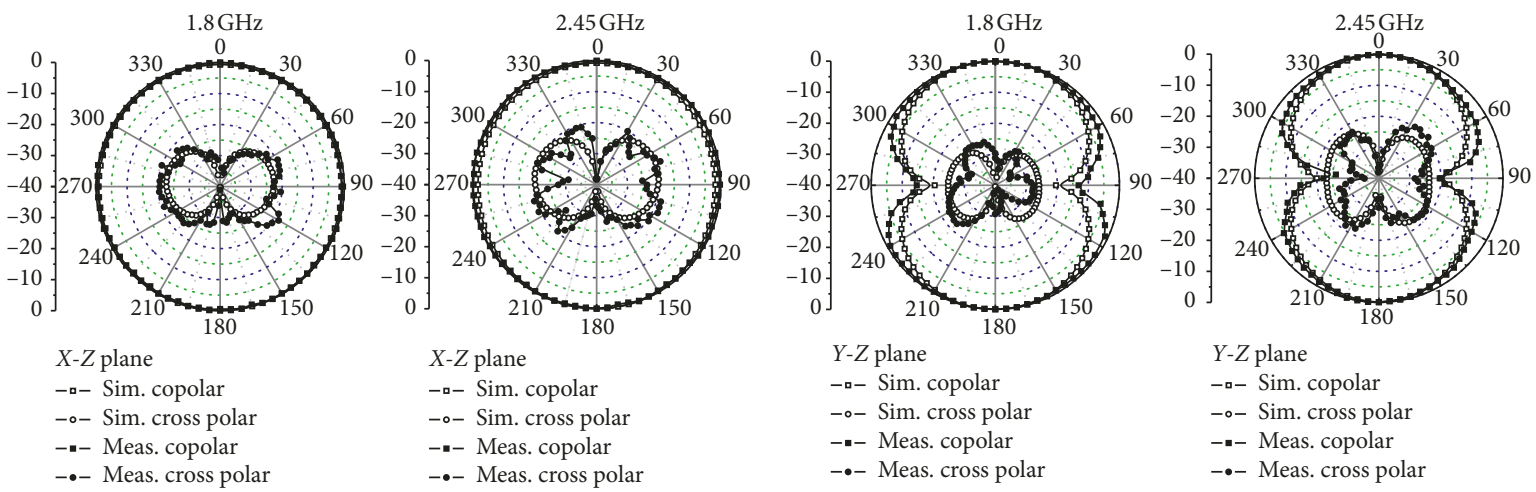

Y-Z plane

$-r-$ Sim. copolar

- - - Sim. cross polar

-. Meas. copolar

-.- Meas. cross polar

-.- Meas. cross polar

-- Meas. cross polar
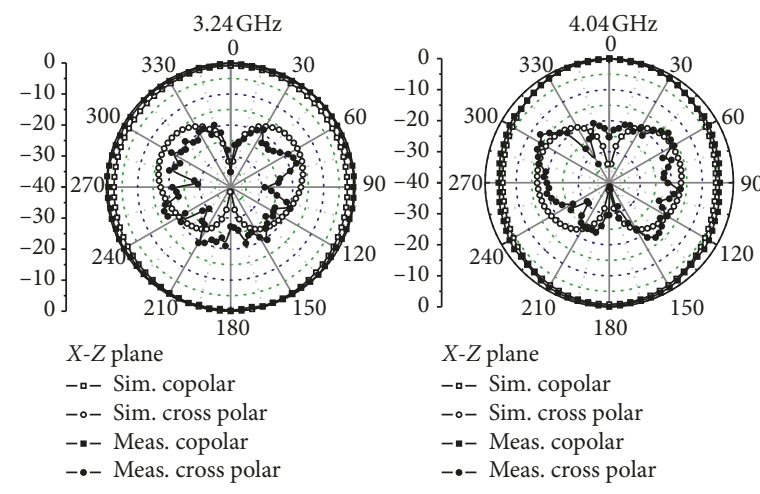

(a)

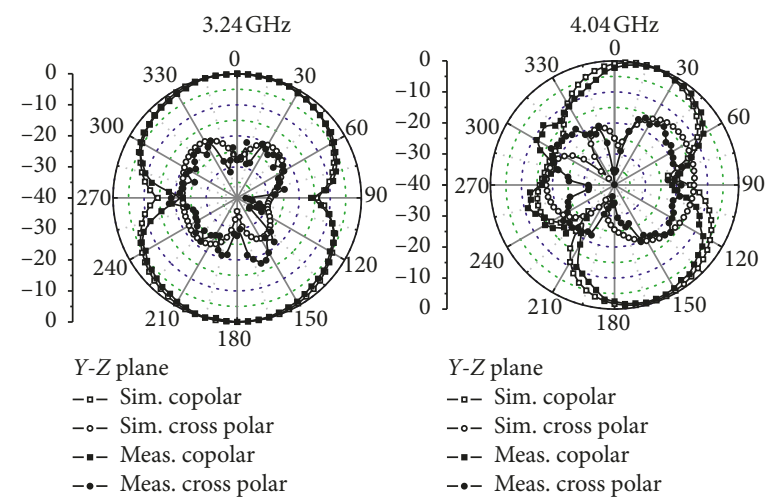

(b)

FiguRE 12: Simulated and measured radiation patterns of the presented antenna at the resonant frequencies of $1.8 \mathrm{GHz}, 2.45 \mathrm{GHz}, 3.24 \mathrm{GHz}$, and $4.04 \mathrm{GHz}$ in (a) $X-Z$ planes and (b) $Y-Z$ planes.

TABLE 2: Comparison between the presented antenna and other designs.

\begin{tabular}{|c|c|c|c|}
\hline References & $\%$ impedance bandwidths $\left(\left|S_{11}\right|\right.$ level $\left.<-10 \mathrm{~dB}\right)$ & Overall dimension $\left(\mathrm{mm}^{3}\right)$ & Radiator type \\
\hline$[11]$ & $\begin{array}{c}22.49 \%(550 \mathrm{MHz} \text { at } 2.45 \mathrm{GHz}), 9.14 \%(320 \mathrm{MHz} \text { at } \\
3.5 \mathrm{GHz}) \text {, and } 17.33 \%(920 \mathrm{MHz} \text { at } 5.3 \mathrm{GHz})\end{array}$ & $100 \times 60 \times 0.8$ & Monopole antenna \\
\hline$[12]$ & $\begin{array}{l}5.1 \%(124 \mathrm{MHz} \text { at } 2.45 \mathrm{GHz}) \text { and } 22.4 \%(1124 \mathrm{MHz} \text { at } \\
5.5 \mathrm{GHz})\end{array}$ & $50 \times 30 \times 1.6$ & Slot and monopole antenna \\
\hline$[21]$ & $\begin{array}{c}35.8 \%(1010 \mathrm{MHz} \text { at } 2.825 \mathrm{GHz}) \text { and } 24.4 \% \\
(1380 \mathrm{MHz} \text { at } 5.65 \mathrm{GHz})\end{array}$ & $69.3 \times 66.2 \times 1.6$ & Monopole antenna \\
\hline [22] & $\begin{array}{c}53.97 \%(1700 \mathrm{MHz} \text { at } 3.15 \mathrm{GHz}) \text { and } 27.59 \% \\
(1600 \mathrm{MHz} \text { at } 5.8 \mathrm{GHz})\end{array}$ & $40 \times 45 \times 1$ & Monopole antenna \\
\hline Proposed antenna & $\begin{array}{c}22.22 \%(400 \mathrm{MHz} \text { at } 1.8 \mathrm{GHz}), 9.8 \%(240 \mathrm{MHz} \text { at } \\
2.45 \mathrm{GHz}) \text {, and } 31.27 \%(1160 \mathrm{MHz} \text { at } 3.71 \mathrm{GHz})\end{array}$ & $36 \times 52 \times 1.6$ & Monopole antenna \\
\hline
\end{tabular}

radiator and the second band is generated by the second mode of the Koch fractal ring resonator, while the third band is created by the first mode of the strip together with the third mode of the rhombic ring radiator. Furthermore, the average gains of the proposed antenna are approximately $2 \mathrm{dBi}$ at the first band and $2.5 \mathrm{dBi}$ at the second and third bands. It has been shown that the radiation patterns are quasi-omnidirectional at all operating frequency bands, while a low cross-polarization is obtained.

\section{Data Availability}

The experimental data used to support the findings of this study are available from the corresponding author upon request.

\section{Conflicts of Interest}

The authors declare that there are no conflicts of interest.

\section{Acknowledgments}

The authors would like to thank the Thailand Research Fund (TRF) under a senior research fund (RTA6080008) for the research grant.

\section{References}

[1] K. Kirti, R. I. Venkata, and V. Pallapa, "Energy efficient scheduling in $4 \mathrm{G}$ smart phones for mobile hotspot application," in Proceedings of the 2012 National Conference on 
Communications (NCC), vol. 2012, p. 5, Kharagpur, India, February 2012.

[2] W. Xiao, T. Mei, Y. Lan, Y. Wu, R. Xu, and Y. Xu, "Triple band-notched UWB monopole antenna on ultra-thin liquid crystal polymer based on ESCSRR," Electronics Letters, vol. 53, no. 2, pp. 57-58, 2017.

[3] C.-Y. Shuai and G.-M. Wang, "A novel planar printed dualband magneto-electric dipole antenna," IEEE Access, vol. 5, pp. 10062-10067, 2017.

[4] S. U. Rehman and M. A. S. Alkanhal, "Design and system characterization of ultra-wideband antennas with multiple band-rejection," IEEE Access, vol. 5, pp. 17988-17996, 2017.

[5] P. Moeikham, C. Mahatthanajatuphat, and P. Akkaraekthalin, "A compact UWB antenna with a quarter-wavelength strip in a rectangular slot for $5.5 \mathrm{GHz}$ band notch," International Journal of Antennas and Propagation, vol. 2013, Article ID 574128, 9 pages, 2013.

[6] P. Moeikham and P. Akkaraekthalin, "A compact printed slot antenna with high out-of-band rejection for WLAN/WiMAX applications," Radioengineering, vol. 25, no. 4, pp. 672-679, 2016.

[7] R. Kumar, R. Khokle, and R. V. S. R. Krishna, "A horizontally polarized rectangular stepped slot antenna for ultra wide bandwidth with boresight radiation patterns," IEEE Transactions on Antennas and Propagation, vol. 62, no. 7, pp. 3501-3510, 2014.

[8] H. Chen, X. Yang, Y. Z. Yin, S. T. Fan, and J. J. Wu, "Triband planar monopole antenna with compact radiator for WLAN/ WiMAX applications," IEEE Antennas and Wireless Propagation Letters, vol. 12, pp. 1440-1443, 2013.

[9] S. Ahmed, F. A. Tahir, A. Shamim, and H. M. Cheema, "A compact Kapton-based inkjet-printed multiband antenna for flexible wireless devices," IEEE Antennas and Wireless Propagation Letters, vol. 14, pp. 1802-1805, 2015.

[10] Y.-J. Chen, T.-W. Liu, and W.-H. Tu, "CPW-fed penta-band slot dipole antenna based on comb-like metal sheets," IEEE Antennas and Wireless Propagation Letters, vol. 16, pp. 202205, 2017.

[11] M.-T. Wu and M.-L. Chuang, "Multibroadband slotted bowtie monopole antenna," IEEE Antennas and Wireless Propagation Letters, vol. 14, pp. 887-890, 2015.

[12] C.-Y. Huang and E.-Z. Yu, "A slot-monopole antenna for dual-band WLAN applications," IEEE Antennas and Wireless Propagation Letters, vol. 10, pp. 500-502, 2011.

[13] J.-H. Lu and B.-J. Huan, "Planar multi-band monopole antenna with L-shaped parasitic strip for WiMAX application," Electronics Letters, vol. 46, no. 10, pp. 671-672, 2010.

[14] P. Xu, Z.-H. Yan, and C. Wang, "Multi-band modified forkshaped monopole antenna with dual L-shaped parasitic plane," Electronics Letters, vol. 47, no. 6, pp. 364-365, 2011.

[15] N. Wongsin, T. Suangun, C. Mahatthanajatuphat, and P. Akkaraekthalin, "A rhombic ring monopole antenna with stripline and ring resonator for multiband operation," in Proceedings of the 14th International Conference on Electrical Engineering/Electronics, Computer, Telecommunications and Information Technology (ECTI-CON), pp. 706-709, Phuket, Thailand, June 2017.

[16] S. R. Best, "On the resonant properties of the Koch fractal and other wire monopole antennas," IEEE Antennas and Wireless Propagation Letters, vol. 1, pp. 74-76, 2002.

[17] D. D. Krishna, M. Gopikrishna, C. K. Aanandan, P. Mohanan, and K. Vasudevan, "Compact wideband Koch fractal printed slot antenna," IET Microwaves, Antennas \& Propagation, vol. 3, no. 5, pp. 782-789, 2009.
[18] A. Farswan, A. K. Gautam, B. K. Kanaujia, and K. Rambabu, "Design of Koch fractal circularly polarized antenna for handheld UHF RFID reader applications," IEEE Transactions on Antennas and Propagation, vol. 64, no. 2, pp. 771-775, 2016.

[19] H.-T. Hsu and T.-J. Huang, "A koch-shaped log-periodic dipole array (LPDA) antenna for universal ultra-high-frequency (UHF) radio frequency identification (RFID) handheld reader," IEEE Transactions on Antennas and Propagation, vol. 61, no. 9, pp. 4852-4856, 2013.

[20] D. H. Werner and S. Gangul, "An overview of fractal antenna engineering research," IEEE Antennas and Propagation Magazine, vol. 45, no. 1, pp. 38-57, 2003.

[21] W.-C. Liu and C.-M. Wu, "Broadband dual-frequency CPWfed planar monopole antenna with rectangular notch," Electronics Letters, vol. 40, no. 11, p. 642, 2004.

[22] H. Huang, Y. Liu, S. Zhang, and S. Gong, "Multiband metamaterial-loaded monopole antenna for WLAN/WiMAX applications," IEEE Antennas and Wireless Propagation Letters, vol. 14, pp. 662-665, 2015. 


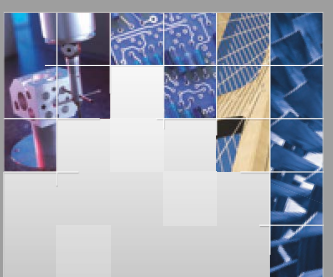

\section{Enfincering}
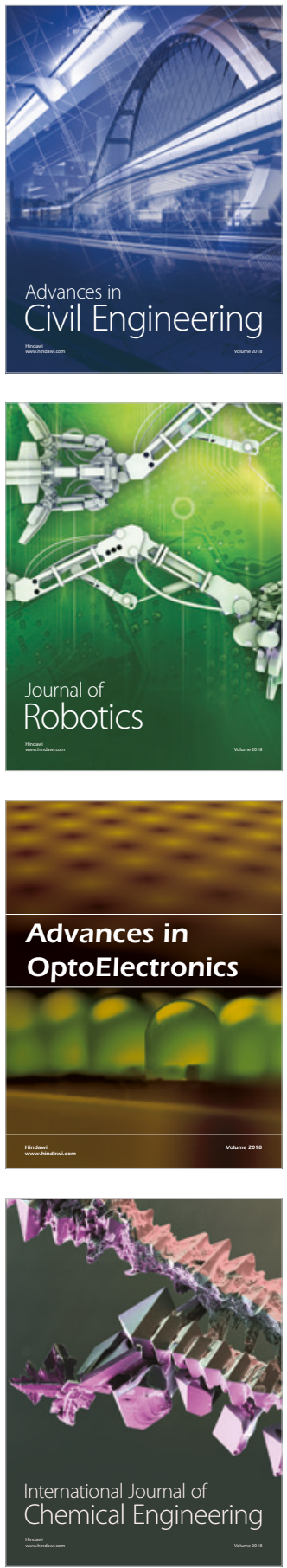

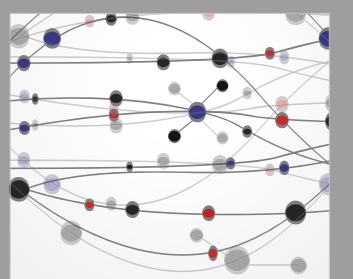

\section{Rotating \\ Machinery}

The Scientific World Journal

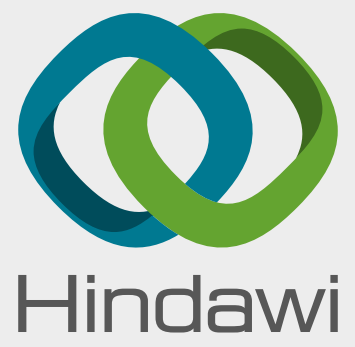

Submit your manuscripts at

www.hindawi.com
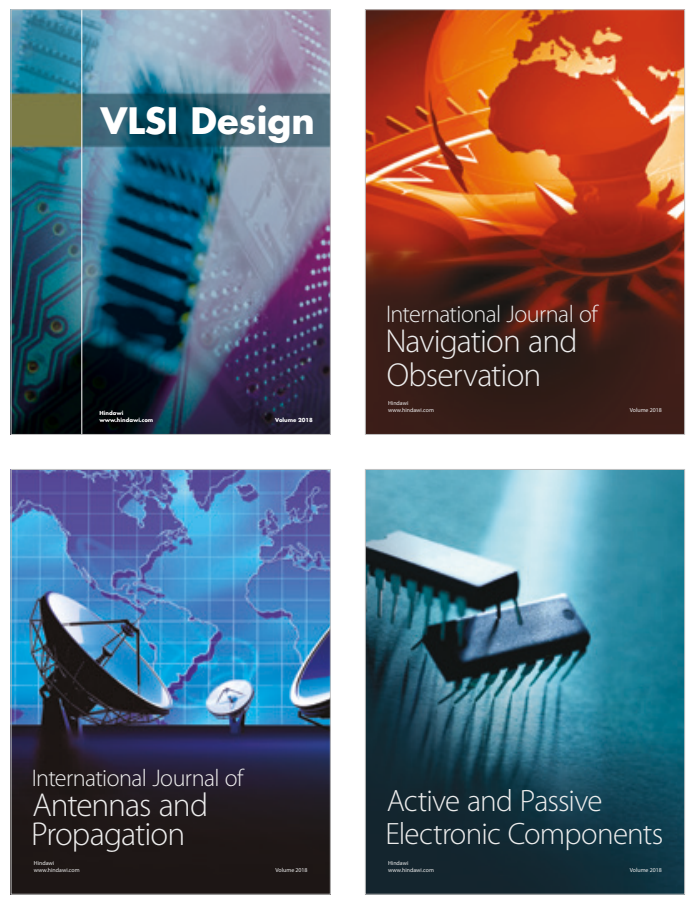
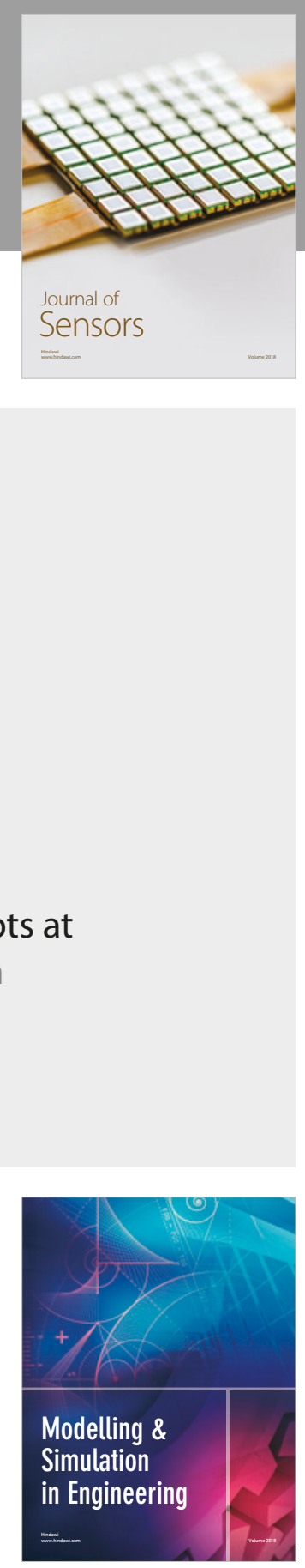

\section{Advances \\ Multimedia}
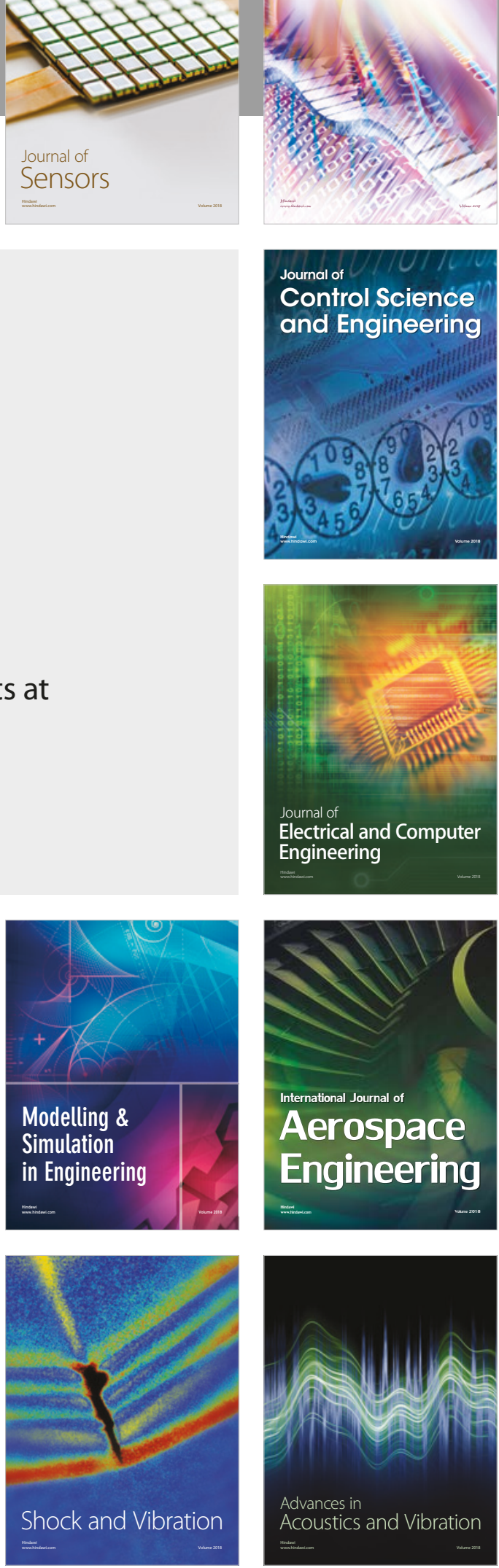